\title{
EDITORIAL
}

\section{VENEREAL DISEASES, THE CHANGING PROBLEM}

A year ago, under the above title*, we commented editorially on the changing emphasis on the different aspects of the work of the venereologist and his message to his colleagues in general medicine, obstetrics, and public health. We concluded then, that " despite to-day's optimism, the venereologist has a responsible future". In the latter part of 1952 some venereologists detected an increase in the number of new cases of urethritis, and the 1952 totals for both gonorrhoea and non-specific urethritis in England and Wales were greater than those for 1951. The quarterly figures for 1953, circulated to the directors of venereal diseases clinics in England and Wales, show an increase of about 8 per cent. in both male and female cases of gonorrhoea in the second quarter as compared with the first quarter of the year. Non-specific urethritis also shares in this increased incidence. While the increase is not perhaps alarming quantitatively, it is important because, for the first time, the post-war downward trend in incidence has not only been halted but has actually been reversed. Succeeding quarterly returns will be watched with special interest. The downward trend of early syphilis continues uninterrupted albeit at slackening tempo but the number of cases of late syphilis remains essentially unchanged.
W. V. Macfarlane (on p. 203 of this issue) describes the result of tracing contacts of late syphilis in the Newcastle area although this practice is unfortunately not yet a routine in all the clinics in the United Kingdom. The further study of defaulting patients by Horne (p. 210) confirms his earlier findings in a smaller seriest, and suggests that there is always a hard core of patients with early syphilis who repeatedly default from treatment. Most venereologists will agree that this tendency for a proportion of patients to default from treatment, after only a few attendances, is widespread. This trait may well encourage the use of a large " sterilizing" dose of P.A.M. as soon as early syphilis has been diagnosed followed by consolidation treatment if the patient continues to attend. It is obvious that in these and other ways the venereologist still has much to do to control venereal disease and its effects. To reduce the present service of the venereal diseases clinics at this time would be of little direct economy and would indirectly cost the country dear. Administrators and others who at present seek such a reduction perhaps fail to appreciate the danger and should pause before shouldering such a responsibility.

* Editorial (1952). British Journal of Venereal Diseases, 28, 159.
† Horne, G. O. (1950). Ibid., 26, 164.

TABLE

NEW CASES REGISTERED FOR THE FIRST TIME IN VENEREAL DISEASES CLINICS IN ENGLAND AND WALES $\ddagger$

\begin{tabular}{c|c|c|c|c|c|c|c}
\hline \multirow{2}{*}{ Year } & \multirow{2}{*}{ Quarter } & \multicolumn{2}{|c|}{ Syphilis } & \multirow{2}{*}{ Urethitis } & \multicolumn{3}{c}{ Gonorrhoea } \\
\cline { 3 - 6 } & & Early & Late & & Male & Female & Total \\
\hline 1952 & 2 & 353 & 1,230 & 3,020 & 4,060 & 822 & 4,882 \\
& 3 & 340 & 1,070 & 3,177 & 4,279 & 978 & 5,257 \\
& 4 & 271 & 1,153 & 2,729 & 3,658 & 928 & 4,586 \\
\hline 1953 & 1 & 279 & 1,069 & 2,834 & 3,328 & 896 & 4,224 \\
& 2 & 245 & 1,068 & 3,326 & 3,723 & 999 & 4,722 \\
\hline
\end{tabular}

$\ddagger$ Abstracted from quarterly totals circularized to Directors of V.D. clinics by the Adviser in Venereology, Ministry of Health. 